\title{
Acellular Pertussis Vaccine: Iran's Next Step to Control the Disease?
}

\author{
Iraj Sedighi $^{1, *}$; Taravat Sadrosadat ${ }^{2}$ \\ ${ }^{1}$ Department of Pediatrics, Faculty of Medicine, Hamadan University of Medical Sciences, Hamadan, IR Iran \\ ${ }^{2}$ Department of Pediatrics, Faculty of Medicine, Tehran University of Medical Sciences, Tehran, IR Iran \\ ${ }^{*}$ Corresponding author: Iraj Sedighi, Department of Pediatrics, Faculty of Medicine, Hamadan University of Medical Sciences, Hamadan, IR Iran. Tel: +98-8112640081, Fax: \\ +98-8112640016, E-mail: sedighi@umsha.ac.ir
}

Received: September 26, 2014; Revised: January 12, 2015; Accepted: January 25, 2015

Keywords: Vaccines; Pertussis Vaccine; Iran

Pertussis is a vaccine preventable disease that causes mortality and morbidity even in vaccination era. This disease causes 60 million cases and over 500000 deaths annually, which is among 10 causes of death in children worldwide $(1,2)$. It is the only preventable disease that still resists our attempts to be controlled (3). The most important source of disease is adults with pertussis in whom the signs and symptoms may not be considerable. Unfortunately, neither the disease nor the vaccination will cause lifelong immunity (2). Since 1948, when whole-cell bordetella pertussis vaccine introduced, we have not been desirably accomplished a success in our battle against the disease (2). Although the prevalence of pertussis has been decreased by pertussis vaccine, vaccination also changed the epidemiology of this disease; that is, the prevalence of pertussis has changed from 1- to 10-year-old children to younger infants and adults. This change in pertussis epidemiology means that more adults are being involved and as a result more young infants will be affected. Waning the effect of vaccination in adolescents and adults plays an important role in the postvaccination pattern of pertussis epidemiology (1). It has been shown that the number of subclinical adult cases transmitting the disease is also considerable (2). Hence, we would not be able to overcome the disease unless we have programs to vaccinate all age groups with several intervals and booster doses (4). Intervals are necessary because it has shown that 12 years after vaccination the protection of vaccine is unremarkable (2).

An accurate record of pertussis incidence is not available in Iran, however, different precious studies have conducted that reflect the epidemiology of pertussis in Iran. One study was done in Hamadan to evaluate the serologic immunity against pertussis among medical student freshmen; it showed that only $47.6 \%$ of them were serologically immune against pertussis (mean level of $71.7 \mathrm{u}$ / $\mathrm{mL}$ ) (5). Another study from 2008 to 2011 was performed on infants, younger than 6 months, referred as a prob- able pertussis cases and 12 out of 138 had positive results for pertussis by PCR (6). In a study in Tehran from 2007 to 2008 , a total of 328 students aged 6 to 14 year with persistent cough were examined for Bordetella Pertussis and Parapertussis by PCR and culture; it showed that 21 of them (6.4\%) had a positive PCR test for B. pertussis and $1.8 \%$ for $B$. parapertussis. Culture results also revealed B. pertussis in four specimens (7). To estimate the protection against pertussis in pregnant women, a study was conducted in Hamadan in which $35 \%$ of participants had positive serology for pertussis (8). Also a multicenter study from 4 different cities in Iran showed that $37.7 \%$ of participants by cut-off point of anti-PT IgG of $80 \mathrm{U} / \mathrm{mL}$ and $31.6 \%$ by cutoff point of $94 \mathrm{U} / \mathrm{mL}$ have positive titers of pertussis antibody that may be due to recent infection (9).

Although the higher incidence of disease in Iran and other parts of the world might be due to modern laboratory equips and disease awareness, non-effective vaccination should also be considered. The concerns of the disease and the attempts toward solving the problem have led to the introduction of different type of vaccine: acellular pertussis vaccine, with the superiority of its safety in adults. However, it was not the end of the story because determining the target age group for revaccinating is not easy. For example, in the USA in order to protect very young infants in their early weeks of life, cocoon strategy (vaccinating all neonate's nearby) was soon replaced by during pregnancy vaccination policy because of the difficulties in adopting cocoon style $(1,10)$. The method recommended by experts in the USA is pregnant women vaccination in conjunction with adult and adolescent revaccination $(3,11)$. Although many studies indicate that whole-cell vaccines provide more and longer immunity compared to the acellular pertussis vaccine, the wholecell vaccines are recommended only for children under 7 years old, and for additional doses acellular vaccine is still needed (12).

In Iran the story differs greatly. Despite different studies 
that address the necessity of vaccination of adults, especially pregnant women we have not yet accessed the acellular pertussis vaccine $(7,8,13)$. This means that we have less protection against this disease compared to Bahrain, Jordon, Kazakhstan, and Qatar in this region. Apparently, it is the time for Iran's health policy makers to adopt a decision for promoting the immunity of Iranian population by bringing new vaccines to Iran's schedule. Considering the above-mentioned data, we believe that besides vaccination of Iranian children with current national vaccination schedule (whole-cell vaccines in children), acellular pertussis vaccine should be used for revaccination of adolescents and adults as booster doses.

\section{Authors' Contributions}

Iraj Sedighi designed the study; Taravat Sadrosadat substantially contributed to data collection; Iraj Sedighi and Taravat Sadrosadat performed data interpretation and drafted the manuscript.

\section{Funding/Support}

This study was supported by Hamadan University of Medical Sciences.

\section{References}

1. Centers for Disease C, Prevention.. Updated recommendations for use of tetanus toxoid, reduced diphtheria toxoid and acellular pertussis vaccine (Tdap) in pregnant women and persons who have or anticipate having close contact with an infant aged $<12$ months -- Advisory Committee on Immunization Practices (ACIP), 2011. MMWR Morb Mortal Wkly Rep. 2011;60(41):1424-6.

2. Long SS. Bordetella pertussis and Bordetella parapertussis. In:
Kliegman RM editor. Nelson text book of pediatrics. 19th ed. Philadelphia: Elsevier; 2011. pp. 944-8.

3. Healy CM, Rench MA, Baker CJ. Implementation of cocooning against pertussis in a high-risk population. Clin Infect Dis. 2011;52(2):157-62.

4. Cherry JD. The present and future control of pertussis. Clin Infect Dis. 2010;51(6):663-7.

5. Hashemi SH, Ranjbar M, Hajilooi M, Seif-Rabiei MA, Bolandi M, Moghimi J. Seroprevalence of Immunoglobulin $G$ antibodies against pertussis toxin among asymptomatic medical students in the west of Iran: a cross sectional study. BMC Infect Dis. 2009;9:58.

6. Hajia M, Rahbar M, Fallah F, Safadel N. Detection of Bordetella pertussis in Infants Suspected to have Whooping Cough. Open Respir Med J. 2012;6:34-6.

7. Ghanaie RM, Karimi A, Sadeghi H, Esteghamti A, Falah F, Armin S, et al. Sensitivity and specificity of the World Health Organization pertussis clinical case definition. Int J Infect Dis. 2010;14(12):e1072-5.

8. Hashemi SH, Zamani M, Mamani M, Javedanpoor R, Rahighi AH, Nadi E. Seroprevalence of Bordetella pertussis antibody in pregnant women in Iran. J Res Health Sci. 2014;14(2):128-31.

9. Sedighi I, Rahimi H, Emadoleslami MS, Fahimzad A, Hosseini F, Afsharian M, et al. Seroepidemiology of Bordetella pertussis Infection in Fresh College Students in Iran: A Multicenter Study. Arch Clin Infect Dis. 2014;9(1).

10. Sedighi I, Sadrosadat T. Comment on: Seroprevalence of Bordetella pertussis Antibody in Pregnant Women in Iran. J Res Health Sci. 2014;14(3):236-7.

11. Healy CM, Rench MA, Castagnini LA, Baker CJ. Pertussis immunization in a high-risk postpartum population. Vaccine. 2009;27(41):5599-602.

12. Klein NP, Bartlett J, Fireman B, Rowhani-Rahbar A, Baxter R. Com parative effectiveness of acellular versus whole-cell pertussis vaccines in teenagers. Pediatrics. 2013;131(6):e1716-22.

13. Shokrollahi MR, Noorbakhsh S, Eizadi A, Monavari HR, Mousavi MJ, Javad Nia S, et al. Searching the B. pertussis (Real Time PCR) in Cases with Prolonged Cough ( $>2$ weeks) in Population with Unvaccinated Adult: A Cross Sectional Study. Tehran, Iran.J Community Med Health Educ. 2013;3:202. 